\title{
EFFECTIVENESS OF URETERIC REIMPLANTATION ON NON-REFLUXING OBSTRUCTIVE CONGENITAL MEGAURETER
}

\author{
SHAFIQUR RAHMAN ${ }^{1}$, MOHAMMAD ABDUL AZIZ1 ${ }^{1}$, MM HASAN ${ }^{1}$, NURUN NAHAR HAPPY2 ${ }^{2}$, TASNEEM \\ MAHJABEEN ${ }^{3}$
}

${ }^{1}$ Department of Urology, BIRDEM General Hospital, Dhaka, ${ }^{2}$ Department of Plastic Surgery and 100 Bed Burn Unit, DMC \& H, Dhaka, ${ }^{3}$ Department of Dermatology, BIRDEM General Hospital, Dhaka

\begin{abstract}
:
Background: One in ten thousand children born with megaureter. A significant portion of this groups are of obstructed variety and the rest are refluxing ureter. It can cause obstructions and back pressure renal damage. Early diagnosis and treatment can stop deterioration of renal function and prevent complications like renal failure. Definitive treatment is uretero-neocystostomy with or without tailoring the ureter.

Objective: Objective of this study was to observe the effectiveness of ureteric reimplantation on non-refluxing obstructive congenital megaureter. To achieve this objective we had observed serum creatinine level pre and postoperatively and assessed structural changes in kidney by ultrasonogram, IVU, MCU and RGP pre and postoperatively. We also observed the split renal function and split GFR of the affected kidney both pre and post operatively.

Methods: This was a cross-sectional observational study. This study comprise of 35 cases of congenital non-refluxing obstructed megaureter, who were admitted in BIRDEM General Hospital and multiple other hospitals in Dhaka city from July 2013 to December 2014. Diagnosis was made by intravenous urography (IVU) reveling a dilated lower third or entire ureter with narrow tapering lower end. Obstruction was also confirmed by diuretic $T c^{99 m}$ DTPA scan. A voiding cystourethrogram was obtained to exclude VUR. Those with poor renal function were evaluated by ultrasonography, DTPA scan and retrograde ureteropyelography.
\end{abstract}

Results: Of 35 patients, 20 were male and 15 were female. Age range 2 to 19 years. All patients underwent ureteric reimplantation, with tailoring in 15 cases. Post-operative mean serum creatinine was $0.99 \pm 0.34$ which showed improvement. Split function in DTPA renogram and split GFR of patient with POM in the affected right side also showed improvement (29.49 \pm 4.02 and $29.64 \pm 4.86)$ as well as affected in left side $(27.77 \pm 4.18$ and 28.02 \pm 5.31$)$.

Conclusion: Ureteral tailoring with an extravesical ureteral reimplantation can be performed safely and effectively for primary obstructive megaureter. It is found that, ureteroneocystostomy ensured free renal drainage and preserved renal function as well as prevented complications and further deterioration.

Bangladesh J. Urol. 2018; 21(1): 20-24

\section{Introduction}

Megaureter is an abnormality of one or both of the ureters. Ureters are two funnel shaped tube that carry urine from kidneys to the bladder. A megaureter refers to an

Correspondence:Dr Shafiqur Rahman, Assistant Professor, Department of Urology, BIRDEM General Hospital, Dhaka Emai: shafiqur04@gmail.com expanded or widened ureter that does not function normally. According to DeFoor et al. (2004) the size of a megaureter is usually greater than $7 \mathrm{~mm}$ in diameter [1]. However, the extent of dilatation varies considerably and in some cases ureter may be as wide as $3 \mathrm{~cm}$ or more in cross-sectional diameter. In nearly all cases the dilatation is present along the entire length of ureter. Complications associated with megaureter include 
reverse flow of urine in to the kidneys and pooling of urine inside the ureter that does not drain. Pooling can cause a child to develop urinary tract infection and in severe case renal failure. According to Shukla et al. (2005) incidence of congenital megaureter is 1 in 10000 [2].

Primary obstructive megaureter first described in 1923 by Caulk ${ }^{[3]}$. The condition is common in children but as a primary presentation is uncommon in adult. The disease is characterized by an intrinsic congenital obstruction at the lower 1 to $2 \mathrm{~cm}$ of the ureter just before it enters the bladder. The ureter above is grossly dilated in it's entirely or partially.

The diagnostic criteria are ${ }^{[4,5]}$ :

- Dilated ureter as seen on intravenous urography, retrograde pyelography, antegrade pyelography, ultrasonography, or magnetic resonance urography;

. Lower end of ureter ending in a smooth taper;

Absence of vesicoureteral reflux;

Absence of infravesical obstruction; and

Absence of organic obstruction at the lower end of the ureter as confirmed by cystoscopy and ureteral catheterization.

The disease is common in children and most may be detected in utero by antenatal ultrasonography. However, more than $50 \%$ of the megaureters regress with time as seen on regular follow-up in children, presumably owing to maturation of the vesicoureteral junction [6-7]. Recurrent infection, pain, or significant deterioration of function is an indication for surgery. However, the disease in adults has a variable course and most present in the third decade of life with reduced function or complications such as secondary calculi, recurrent infection, or reduced function.

\section{Methodology:}

It was a cross-sectional observational study and was carried out in the Department of Urology, BIRDEM General Hospital and other multiple hospitals in Dhaka city from July 2013 to December 2014. The study included patients having voiding complains who underwent USG of KUB which revealed the dilatation of upper urinary tract. Those patients are diagnosed by imaging as obstruction at distal ureter (Patients having HDUN on USG or IVU), obstructive curve on diuretic renogram, no VUR on MCU; were included in this study. Dilated ureter due to any luminal obstruction by a stone foreign body, tumor or compression from outside, refluxing megaureter were excluded.

\section{Procedure:}

All patients underwent ureteroneocystectomy under general anesthesia over DJ stent. In 25 unilateral cases and preferably where extensive tailoring was required, extravesical Lich-Grégoire method was followed. In 5 bilateral cases Cohen's cross-trigonal reimplantationand was done by a single Pfannenstiel incision through extraperitoneal approach. In 5 patient of younger age group having unilateral POM with wider abdomen and shallower pelvis underwent intravesical LeadbetterPolitano neoureterocystostomy. In 15 patients tailoring of distal ureter was required for effective reimplantation. DJ stent was used and removed two months postoperatively.

Post-operatively patients were followed up at three months with urine culture, serum creatinine and DTPA renogram. At 6 months post-operatively IVU with MCU or RGP was done.

\section{Results}

In our study total patient was 35 . Male patient were 20 $(57 \%)$ and female $15(43 \%)$. Age range was 2 years to 19 years. Six patients were asymptomatic and was diagnosed incidentally. Other presenting complaints were; loin pain $(10=28 \%)$, recurrent UTI $(26=74 \%)$, abdominal mass $(1=3 \%)$, haematuria $(2=6 \%)$ and impaired renal function $(2=6 \%)$.

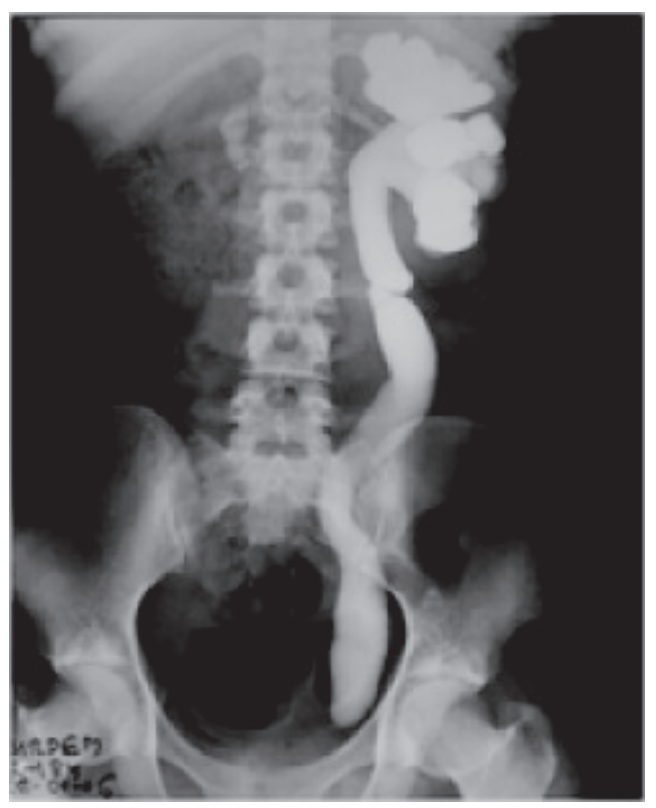

Figure 1: IVU showing left sided primary obstructed megaureter in 10yrs old child (personal series) 


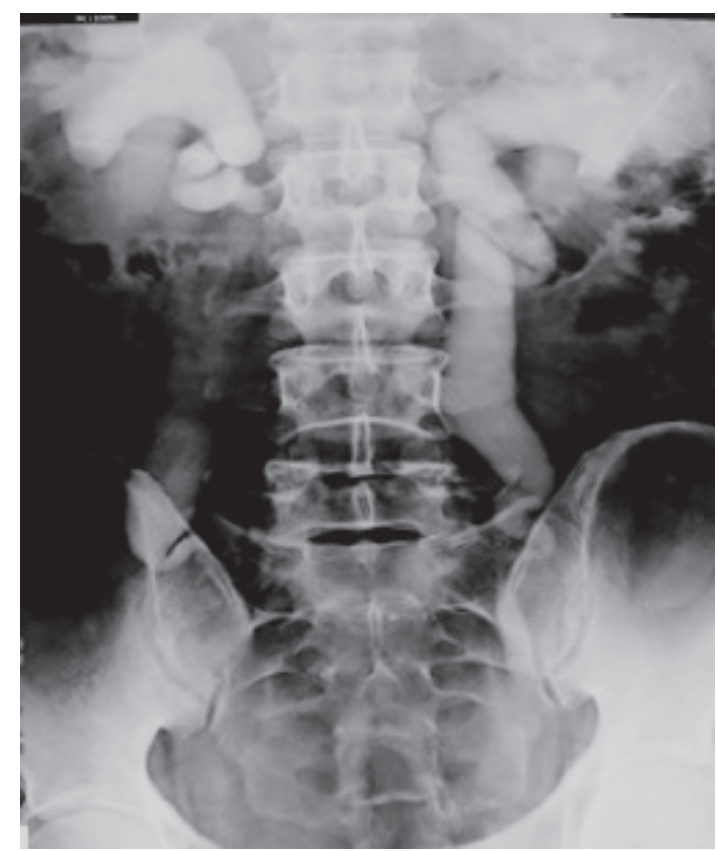

Figure 2: IVU showing bilateral POM (personal series)
Table 1 showing comparison of pre and post-operative split function and GFR between two age groups and two operative approaches on the affected right kidney $(n=17)$. Observation showed bulk of the patients were on 2-10 years $(n=15)$ and most of them were underwent extravesical ureteric reimplantation $(n=12)$. Their postoperative split function and GFR showed statistically significant improvement.

Table 2 showing comparison of pre and post-operative split function and GFR between two age groups and two operative approaches on the affected left kidney $(n=13)$. Observation showed 10 patients were $2-10$ years and 3 were 11-19 years. Extravesical ureteric reimplantation was done in 11 patients and intravasical in 2 patients. There was significant postoperative improvement of split function and GFR in extravesical approach.

Table -I Comparison of parameters in affected right kidney $(n=17)$

\begin{tabular}{lllcc}
\hline Biochemical parameters & Age group & & Preoperative & Postoperative \\
\hline DTPA with spilt function (right) (\%) & $2-10$ yrs $(n=15)$ & Extravesical $(n=12)$ & $23.68 \pm 3.27$ & $28.52 \pm 3.69$ \\
& & Intravesical $(n=3)$ & $26.43 \pm 2.69$ & $30.93 \pm 4.61$ \\
& \multirow{2}{*}{$11-19 \mathrm{yrs}(\mathrm{n}=2)$} & Extravesical $(\mathrm{n}=2)$ & $27.30 \pm 2.97$ & $33.20 \pm 4.67$ \\
& & Intravesical $(\mathrm{n}=0)$ & - & - \\
GFR $(\% \mathrm{ml} / \mathrm{min})$ (right) & \multirow{2}{*}{$2-10 \mathrm{yrs}(\mathrm{n}=15)$} & Extravesical $(\mathrm{n}=12)$ & $21.43 \pm 2.60$ & $27.99 \pm 4.36$ \\
& & Intravesical $(\mathrm{n}=3)$ & $24.50 \pm 2.0$ & $32.37 \pm 4.26$ \\
& \multirow{2}{*}{$11-19 \mathrm{yrs}(\mathrm{n}=2)$} & Extravesical $(\mathrm{n}=2)$ & $25.25 \pm 2.47$ & $35.45 \pm 3.18$ \\
& & Intravesical $(\mathrm{n}=0)$ & - & - \\
\hline
\end{tabular}

Table 2: Comparison of parameters in affected left kidney $(n=13)$

\begin{tabular}{lllcc}
\hline Biochemical parameters & Age group & & Preoperative & Postoperative \\
\hline DTPA with spilt function (left) $(\%)$ & $2-10$ yrs $(n=10)$ & Extravesical $(n=8)$ & $23.19 \pm 2.89$ & $26.74 \pm 3.03$ \\
& & Intravesical $(n=2)$ & $20.65 \pm 2.62$ & $23.75 \pm 2.05$ \\
& \multirow{2}{*}{$11-19 \mathrm{yrs}(\mathrm{n}=3)$} & Extravesical $(\mathrm{n}=3)$ & $28.17 \pm 1.53$ & $33.20 \pm 2.46$ \\
& & Intravesical $(\mathrm{n}=0)$ & - & - \\
GFR $(\% \mathrm{ml} / \mathrm{min})$ (left) & \multirow{2}{*}{$2-10 \mathrm{yrs}(\mathrm{n}=10)$} & Extravesical $(\mathrm{n}=8)$ & $20.70 \pm 2.63$ & $26.71 \pm 3.77$ \\
& & Intravesical $(\mathrm{n}=2)$ & $18.60 \pm 2.69$ & $22.55 \pm 2.47$ \\
& \multirow{2}{*}{$11-19 \mathrm{yrs}(\mathrm{n}=3)$} & Extravesical $(\mathrm{n}=3)$ & $25.40 \pm 1.04$ & $35.13 \pm 1.95$ \\
& & Intravesical $(\mathrm{n}=0)$ & - & - \\
\hline
\end{tabular}




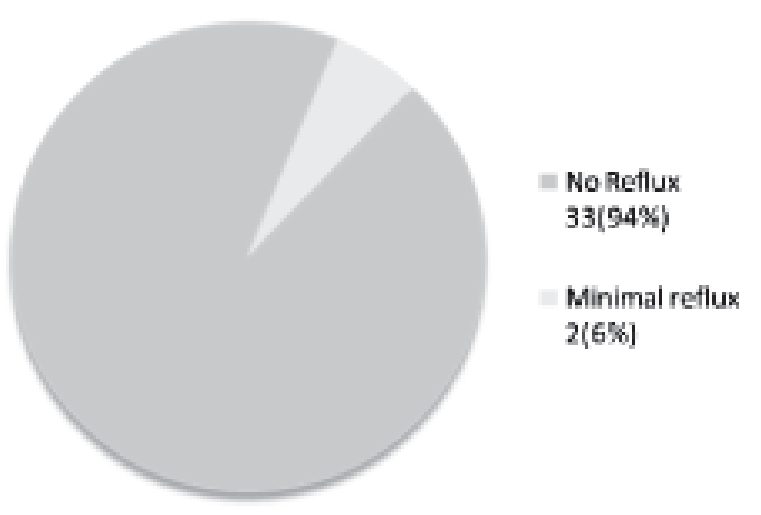

Figure 3: Post-operative IVU \& MCU

In this figure postoperative IVU and MCU done at six month, showing free renal drainage without any reflux in $94 \%(n=33)$ cases minimal reflux in $6 \%(n=2)$.

\section{Discussion}

POM is about one sixth as common as primary pelviureteric junction obstruction. Obstruction appears to result from faulty peristalsis of this segment and histologic studies have demonstrated increased circular muscle and fibrosis in that segment. With the widespread use of obstetric ultrasonography, the incidence of fetal hydronephrosis has been reported more frequently. Conservative management is safe for primary megaureter detected in asymptomatic neonates, because most of these cases show spontaneous regression during prolonged follow-up. However, when surgical intervention is indicated (repeated infection, back pain and deterioration of renal function), the results have been good for ureteroneocystostomy for primary obstructive megaureter in children. Primary obstructive megaureter of adults is characterized by a functional obstruction of the juxtavesical ureter. The condition usually presents in the third or fourth decades of life.

$\mathrm{POM}$ is more common in male than female. The disease is usually unilateral with slight predominance in left ${ }^{[8]}$. In our series, most patients had unilateral disease $(n=30)$ with a right left ratio of 17:13. Right sided POM was found predominatnt in the series of Giovanni et al. done from 2009 to $2010^{[9]}$.

Open surgery remains the gold standard because of excellent success rates ${ }^{[10,11]}$. In our study, all patient underwent open ureteroneocystectomy under general anesthesia over DJ stent. There were no significant post- operative complications except minor wound infection in seven cases and UTI in five cases which were treated appropriately. This result is more or less similar to previous international studies $[8,12]$.

Serum creatinine was done in all patients both pre and postoperatively. In most of the cases it was in normal range because in our series most of POM was unilateral and patient was in earlier age group. Mean serum creatinine was compared pre and postoperatively and showed improvement.

Most common complication after surgery was UTI which was observed in multiple internationally published studies. In the series of Gimpel et al. 45\% patients developed postoperative UTI and hospitalization required in 30\% cases; while in series of Garc1'a et al. (2013) $25 \%$ developed postoperative UTI. In our study, after 3 months urine culture was positive in five cases (14\%) $[13,14]$.

Ultrasonogram of KUB region was done in every patient pre and postoperatively to see the structural changes. There was improvement in HDUN 3 months after surgery. Garc1'a et al. operate on 12 cases of POM and showed statistically significant improvement of HDUN on USG in all patients ${ }^{[14]}$. Bondarenko studied on laparoscopic extravesical ureteric reimplantation in 10 patients of POM and showed that there was significant improvement of HDUN on USG done 3 months postoperatively [15].

DTPA renogram with split function with split GFR was done preoperatively and 6 months postoperatively. Split function and split GFR of patient with POM in right side showed improvement $(29.49 \pm 4.02$ and $29.64 \pm 4.86)$. Patient affected in left side also showed improvement (27.77 \pm 4.18 and $28.02 \pm 5.31)$. In bilateral cases there was improvement in serum creatinine level $(1.48 \pm 0.58)$. Several previous study also show similar result $[14,16]$.

IVU with MCU was done all cases except CKD patients in which cases RGP was done both preoperatively and 6 months postoperatively. MCU confirm that there was no reflux in any cases. Obstruction was also confirmed by DTPA renogram with split function along with split GFR. In our study, at six months post-operatively IVU with MCU or RGP was done. In 94\% cases kidney drains normally without any obstruction or reflux. In $6 \%$ cases there were mild reflux and those patients are kept in close supervision. Torino et al. studied 5 children with POM and showed that there were free renal drainage without any obstruction or reflux postoperatively at 4 months on voiding cystourethrogram and diuretic 
renogram ${ }^{[9]}$. Hemal et al. studied on 55 patients with POM with excellent result in 51 cases, and only 4 patients required revision surgery ${ }^{[8]}$.

Primary obstructive megaureter in adults is different from that encountered in childhood. The growth and maturation of the vesicoureteral junction and the kidney are complete in adults and therefore little spontaneous improvement can be anticipated, unlike that observed in children. It is therefore evident that the adult megaureter requires a more aggressive surgical approach than primary obstructive megaureter observed in the pediatric population. Surgical correction relieves obstruction and improves drainage and although renal functional improvement may not be substantial, further deterioration and complications are prevented ${ }^{[8]}$.

\section{Conclusion:}

Ureteral tailoring with an extravesical ureteral reimplantation can be performed safely and effectively for primary obstructive megaureter. Patient with bilateral involvement and younger patient may benefit from an intravesical ureteral reimplantation. It is found that, ureteroneocystostomy ensured free renal drainage and preserved renal function as well as prevented complications and further deterioration. However, larger series with long term follow up are necessary to validate this result.

\section{References:}

1. Defoor W, Minevich E, Reddy P, et al. (2004) Results of tapered ureteral reimplan-tation for primary megaureter: extravesical versus intravesical approach. J Urol. 172 (4). p.1640-3.

2. Shukla AR, Cooper J, Patel RP, et al. (2005) Prenatally detected primary megaureter: a role for extended followup. J Urol. 173(4). p.1353-6.

3. Caulk JR. (1923) Megaloureter: the importance of the ureterovesical valve. J Urol 9. p.315-319,.

4. Atala A, And Keating Ma. (1992) Vesicoureteral reflux, megaureter and ureteric reimplantation, in Walsh PC, Retik AB, Vaughan Jr. et al. (eds.). Campbell's Urology, 6th ed. Philadelphia, WB Saunders, vol 2, p.1708-1733.

5. Kelalis PP, King LR, And Belman AB: Megaureter, Kelalis PP, King LR, and Bellman. (1976) in Clinical
Paediatric Urology. Philadelphia, WB Saunders. vol 1. p.266-280.

6. Tokunaka S, Koyanagi T, Tsuji I, et al (2008) Histopathology of the nonrefluxing megaureter, a clue to its pathogenesis. J Urol 127. p.328-330.

7. Pitts WR, and Muecke EC. (1975) Congenital megaloureter: a review of 80 patients. J Urol 111. p.468-473.

8. Hemal A. K., Ansari M. S., Doddamani D., Gupta N. P. (2003) Symptomatic and complicated adult and Adolescent primary obstructive Megaureterindications for surgery: analysis, Outcome, and follow-up. Urology 61. p. 703-707.

9. Giovanni Torino, Giuseppe Collura, Ermelinda Mele, Maria Carmen Garganese, Nicola Capozza. (2012) Severe primary obstructive megaureter in the first year of life: preliminary experience with endoscopic balloon dilation. Journal Of Endourology. 26 (4). p.325-329.

10. Suzuki Y, Einarsson Jl. Congenital megaureter. Rev Obstet Gynecol.1(4): 152-3.

11. Simoni F, Vino L, Pizzini C et-al. (2000) Megaureter: classification, pathophysiology, and management. Pediatr Med Chir. 22 (1). p.15-24.

12. Shokeir AA, Nijman RJ. (2000) Primary megaureter: current trends in diagnosis and treatment. BJU Int. 86 (7). p.861-8.

13. Gimpel C, Masioniene L, Djakovic N, Schenk Jp, Haberkorn U, Tönshoff B, Schaefer F. (2010)

14. Garci'A-Smith, M. Bejarano, I. De Haro, J.M. Ribo'. (2013) Use of high-pressure balloon dilatation of the ureterovesical junction instead of ureteral reimplantation to treat primary obstructive megaureter: Is it justified? Journal of Pediatric Urology 9. p.1229-1233.

15. Sergey Bondarenko. (2013) Laparoscopic extravesical transverse ureteral reimplantation in children with obstructive megaureterJournal of Pediatric Urology 9. p.437 - 441.

16. Guse-nov Eia. (2000) Long-term results of the surgical treatment of primary obstructive megaureter in children. Urologiia. Sep-Oct. (5). p.35-40. 